\title{
Seroprevalence survey of brucellosis among rural people in Mongolia
}

\author{
Selenge Tsend, ${ }^{a}$ Zolzaya Baljinnyam, ${ }^{b}$ Bujinlkham Suuri, ${ }^{a}$ Enkhbayar Dashbal, ${ }^{a}$ Baatarkhuu Oidov, ${ }^{c}$ Felix Roth, ${ }^{d}$ \\ Jakob Zinstag, ${ }^{\mathrm{d}}$ Esther Schelling ${ }^{\mathrm{d}}$ and Davaalkham Dambadarjaac \\ Correspondence to Selenge Tsend (e-mail: tsendselenge2000@yahoo.com).
}

Background: After the transition from socialism to a market economy in 1990, human brucellosis re-emerged in Mongolia. The aim of our study was to estimate a representative seroprevalence of Brucella spp. and to determine risk factors for brucellosis seropositivity among rural people.

Methods: A cross-sectional study with multistage random selection was conducted in eight provinces of Mongolia. Study participants were interviewed using a questionnaire to obtain their brucellosis history, current symptoms and likely risk factors. Blood samples were drawn to determine brucellosis seroprevalence.

Results: A total of 2856 randomly selected rural people aged four to 90 years were enrolled in the study. The seroprevalence of Brucella spp. was $11.1 \%$ (95\% confidence interval [Cl]: $10.0-12.1$ ), ranging between $2.3 \%$ and $22.6 \%$ in the eight provinces; $39.2 \%(n=609)$ of nomadic camps had at least one seropositive participant. Risk factors associated with brucellosis seropositivity were being older than 45 years (adjusted odds ratio $[\mathrm{AOR}]=6.9,95 \% \mathrm{Cl}=5.1-8.7$ ) and being a veterinarian $(\mathrm{AOR}=2.8,95 \% \mathrm{Cl}=1.5-5.0)$.

Conclusion: Our study confirms that human brucellosis seroprevalence among rural people in Mongolia is high. Human brucellosis can be effectively controlled if high-coverage livestock mass vaccination is implemented with a coverage survey after the vaccinations to ensure completeness. This mass vaccination should be accompanied by public awareness and educational programmes.

$\mathrm{B}$ rucellosis is a zoonosis, and the infection is almost invariably transmitted by direct or indirect contact with infected animals or their products. It is an important human disease in many parts of the world, especially in the Mediterranean countries of Europe, North and East Africa, the Middle East, South and Central Asia and Central and South America. ${ }^{1}$

Brucellosis is caused by members of the Brucella genus. Transmisson of infection to humans occurs through breaks in the skin, following direct contact with tissues, blood, urine, vaginal discharges, aborted fetuses or placentas. $^{2}$ The most frequent symptoms of brucellosis are fever, chills or shaking, malaise, generalized aches and pains all over the body, joint and low back pain, headaches, anorexia, easy tiredness and general weakness. ${ }^{3}$

Mongolia has the second highest incidence of human brucellosis worldwide; another seven republics of the former Soviet Union are included in the
25 countries with the highest incidence. According to data from the National Statistical Office of Mongolia, a rapid increase in notified cases of brucellosis was observed between 1990 and 2000. The increase may have been the result of the evolution from a socialist state to a free market economy which led to the loss of rigorous livestock control. ${ }^{4}$ During this period, changes to the health system precluded early recognition of the disease or interventions that considered the emerging trends in humans and animals. ${ }^{5}$ In Mongolia, factors contributing to the incidence of brucellosis include traditional eating habits, standard hygiene measures, methods for processing milk and its products and rapid movement of animals. ${ }^{3}$

In 2011, a national brucellosis serosurvey was conducted that sampled 168027 head of livestock from 11528 nomadic camps (two to more than four herder families that share the same pasture and water source) of 337 districts of 21 provinces. ${ }^{6}$ Twenty-one provinces, $57.3 \%$ of all districts and $8.0 \%$ of all nomadic camps

\footnotetext{
National Centre for Communicable Diseases of Mongolia

Animal Health Project of Swiss Development Agency in Mongolia

National University of Medicine, Mongolia.

Swiss Tropical and Public Health Institute, Basel, Switzerland.

Submitted: 2 January 2014; Published: 11 November 2014

doi: 10.5365/wpsar.2014.5.1.002
} 
Figure 1. Map of Mongolia by province highlighting provinces where the study was conducted

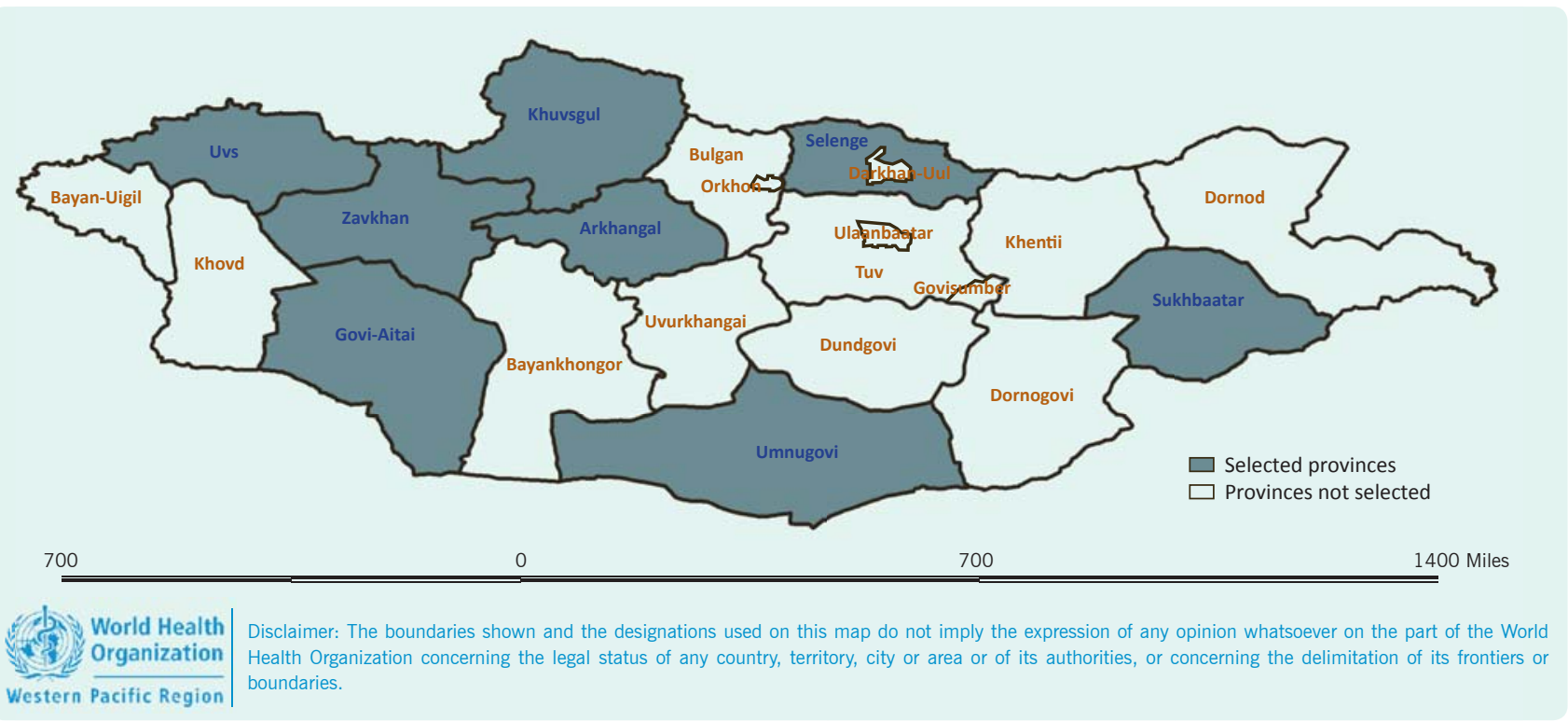

had seropositive livestock including camels, cattle, sheep and goats. Livestock seroprevalence was found in $0.7 \%$ of camels, $1.8 \%$ of cattle, $0.7 \%$ of sheep and $0.5 \%$ of goats using parallel interpretations of Rose Bengal Tests (RBT), complement fixation tests and competitiveenzyme-linked immunoabsorbent assay (ELISA). ${ }^{6}$

The aim of our study was to estimate the seroprevalence of Brucella spp. and to determine risk factors for brucellosis seropositivity among rural people.

\section{METHODS}

\section{Study design and population}

Eight provinces were selected for the cross-sectional surveys. Between June and September 2010, surveys were conducted in Sukhbaatar and Zavkhan provinces, selected for convenience. ${ }^{7}$ Between November 2011 and January 2012, the same surveys were conducted in a further six provinces: Arkhangai, Khuvsgul, Selenge, Uvs, Umnugovi and Govi-Altai (Figure 1). In each province, four districts were selected using simple randomization in Excel (the rand () command). Twenty nomadic camps and four to five individual participants were randomly selected based on the required sample size.

The cluster sample size calculation as described elsewhere ${ }^{7}$ assumed a human brucellosis seroprevalence among Mongolian rural people of $20 \%{ }^{8}$ In addition, the number of clusters and number of individuals per cluster was optimized according to the feasibility and the available budget.

The study was approved by the Ethics Committee of the Health Sciences University of Mongolia and the Ethics Committee of the Canton of Basel of Switzerland. All participants were informed about the study and what they could expect regarding diagnosis, reporting and treatment; all signed a consent form. A child younger than 16 years of age was included in the study with signed consent from of his/her parents.

\section{Data collection}

\section{Study questionnaire}

All study participants were interviewed using a questionnaire which included demographics, risk factors and clinical symptoms for brucellosis. The questionnaire was pre-tested during the 2010 study in Sukhbaatar and Zavkhan ${ }^{7}$ and revised for the extended study to improve understanding of questions and to eliminate overlysensitive questions.

\section{Blood sample collection and handling}

Venous blood was taken with $5 \mathrm{ml}$ Vacutainer ${ }^{\circledR}$ tubes. The blood samples were centrifuged in 3000 rounds per minute for five minutes. Separated $1.5 \mathrm{ml}$ tubes of serum were kept in a cool box and transported to the provincial laboratories for storage and cooling before shipment 
Table 1. Number of participiants seropositive for Brucella spp.* by province, Mongolia, 2010 to 2012

\begin{tabular}{lccccc}
\hline \multicolumn{1}{c}{ Province } & $\begin{array}{c}\text { Number of } \\
\text { districts surveyed }\end{array}$ & $\begin{array}{c}\text { Number of } \\
\text { participants }\end{array}$ & Seropositives & \% of positivity* & $\begin{array}{c}\text { 95\% confidence } \\
\text { interval }\end{array}$ \\
\hline Khuvsugul & 4 & 400 & 46 & 11.5 & $8.72-14.2$ \\
Umnugovi & 4 & 400 & 49 & 12.3 & $9.64-14.9$ \\
Govi-Altai & 4 & 398 & 30 & 7.5 & $4.17-10.8$ \\
Selenge & 4 & 391 & 60 & 15.3 & $12.9-17.6$ \\
Arkhangai & 4 & 400 & 9 & 2.3 & $0.45-9.15$ \\
Uvs & 3 & 293 & 17 & 5.8 & $1.27-10.3$ \\
Sukhbaatar & 4 & 318 & 72 & 22.6 & $20.5-24.6$ \\
Zavkhan & 4 & 256 & 33 & 12.9 & $9.7-16.1$ \\
Total & 31 & 2856 & 316 & 11.1 & $10.0-12.1$ \\
\hline
\end{tabular}

to the serological laboratory of the National Center for Communicable Diseases in Ulaanbaatar where they were tested for brucellosis.

\section{Serological test}

Sera were tested with the RBT for detection of antibodies to Brucella abortus/melitensis from Tulip Diagnostic Ltd (Bambolim, India). Positive sera were re-tested with the RBT using $1 / 2$ to $1 / 32$ serum dilutions, ${ }^{9}$ and with enzyme immunoassay for the qualitative determination of IgG class antibodies against Brucella from the NovaTec Immundiagnostica GmbH (Dietzenbach 63128 Germany). The ELISA test was performed according to manufacturer's instruction.

\section{Data entry and statistical analysis}

All data were double-entered in Access 2007, compared in Epi Info ${ }^{\mathrm{TM}} 3.5$ to correct entry errors and analysed using STATA 10.1. Study participants who tested positive by either ELISA or RBT were considered seropositive for the statistical analysis.

To assess the association between risk factors and human brucellosis seropositivity we used Pearson $\chi^{2}$ or Fisher's exact tests for explanatory variables such as demographics, behaviour-related risk factors and reported clinical symptoms. We also conducted univariate logistic regression using the binary serological outcome with the xtgee command and random effect on the nomadic camp level. A multivariate logistic regression model (with random effect at the nomadic camp) using backward stepwise selection and a removal level for covariates at $P=0.10$ based on the likelihood- ratio test was then constructed. Variables with $p$ values less than 0.05 in the univariate analysis were included in the multivariate model.

To determine the proportion of the general population seroconverting each year due to brucellosis exposure, the seroprevalence data were divided by the duration of seropositivity, assumed to be 10.9 years. ${ }^{10}$ Using a conservative estimate of $20 \%$ of seroconversions representing true clinical cases (note that among all seropositives detected, $58.5 \%$ had at least two symptoms and $31.5 \%$ had at least three symptoms at time of interview), these proportions were multiplied by 0.3 and converted to rates per 100000 for the general population.

\section{RESULTS}

There were 2856 study participants from 609 nomadic camps from 31 districts in the eight selected provinces between four and 90 years of age (median 38 years). This included 2260 (79.1\%) herders, 142 (5.0\%) students, 96 (3.4\%) office workers, 70 (2.5\%) workers, $37(1.3 \%)$ retired people, $20(0.7 \%)$ veterinarians, $18(0.6 \%)$ entrepreneurs, 16 (0.6\%) unemployed adults, $13(0.5 \%)$ children under six years, and 184 (6.4\%) other residents.

\section{Seroprevalence}

The seroprevalence of Brucella spp. among participants was $11.1 \%(95 \% \quad \mathrm{Cl}: \quad 10.0-12.1)$ ranging from $2.3 \%$ to $22.6 \%$ in the eight provinces (Table 1 ) and $4.1 \%$ to $43.8 \%$ in the 28 districts. Within nomadic camps, 39.2\% (95\% Cl: 38.2-41.0) had at least one 
Table 2. Number of nomadic camps with members seropositive for Brucella spp., Mongolia, 2010 to 2012

\begin{tabular}{lcccc}
\hline \multicolumn{1}{c}{ Province } & $\begin{array}{c}\text { Number of nomadic } \\
\text { camps surveyed }\end{array}$ & Positive & \% of positivity* & $\begin{array}{c}\text { 95\% confidence } \\
\text { interval }\end{array}$ \\
\hline Arkhangai & 79 & 7 & 8.9 & $1.89-15.9$ \\
Govi-Altai & 80 & 28 & 35.0 & $32.0-37.9$ \\
Khuvsgul & 82 & 35 & 42.7 & $40.2-45.1$ \\
Umnugovi & 80 & 33 & 41.3 & $38.1-44.5$ \\
Uvs & 58 & 13 & 22.4 & $17.5-27.2$ \\
Selenge & 78 & 40 & 51.3 & $49.1-53.4$ \\
Sukhbaatar & 83 & 56 & 67.5 & $65.9-69.0$ \\
Zavkhan & 69 & 27 & 39.1 & $36.1-42.0$ \\
Total & 609 & $\mathbf{2 3 9}$ & $\mathbf{3 9 . 2}$ & $\mathbf{3 8 . 2 - 4 1 . 0}$ \\
\hline
\end{tabular}

* Based on parallel interpretation of the RBT and ELISA test

to four seropositive members (Table 2). This equated to an annual incidence of seroconversion of 1145 per 100000 and an overall annual incidence of 229 clinical cases per 100000 .

Seroprevalence was higher in females than in males (11.2\% compared with $10.9 \%, P=0.029$ ). By age group, the highest seroprevalence was found in those 45 years and above at $15.5 \%(95 \% \mathrm{Cl}: 13.9-17.0)$, with the lowest in the four to 10 year age group at $2.6 \%$ (95\% Cl: 1.5-20.4). All occupation categories included seropositive cases ranging between $2.8 \%$ and $30.0 \%$ (Table 3).

\section{Analysis of risk factors for brucellosis}

Risk factors associated with being seropositive in univariate analysis included: being 45 years old and above (odds ratio $[\mathrm{OR}]=6.6, P=0.046$ ), being a veterinarian $(\mathrm{OR}=3.5, P=0.016)$, contact with aborted animal fetuses and placentas (OR $=1.35$, $P=0.016)$ and consumption of undercooked liver (OR $=1.51, P=0.001)$ (Table 3).

In the multivariate analysis, only two variables remained associated with being seropositive: being 45 years old and above (adjusted odds ratio $[A O R]=6.9$, $95 \% \mathrm{Cl}: 5.1-8.7)$ and being a veterinarian $(\mathrm{AOR}=2.8$, $95 \% \mathrm{Cl}: 1.5-5.0)$. Among veterinarians who participated in the study, $72.7 \%$ assisted in livestock obstetric work, and $50 \%$ had direct contact with aborted animal fetuses and placentas. The risk factors for veterinarians was also much higher compared with other occupations $(P<0.001)$.
History of human brucellosis and clinical symptoms

Of the study participants, $2.7 \%(n=76)$ reported receiving treatment for human brucellosis in the past; the median time since past brucellosis treatment was 14 years ( $Q 1=3.3$ and $Q 3=20$ years). With the exception of testicular pain, there were significant differences between age groups in reporting clinical symptoms; the age groups of 20 to 44 years and 45 years and above reported more clinical symptoms for human brucellosis. Females also reported more headaches; joint, back and muscle pain; weakness and sleeping disturbances than males (Table 4).

Reported clinical symptoms at the time of the study were compared to the sero-status of participants. Overall, 165 of the 316 (52.2\%) brucellosis seropositive participants and 1186 of the 2540 (46.7\%) seronegative participants reported symptoms. Among all seropositives, $36.7 \%$ reported more than three symptoms; among the seronegatives, $23.1 \%$ reported more than three symptoms $(P<0.001)$. Headache; joint, back and muscle pain; night sweats and sleeping disturbances were significantly associated with brucellosis seropositivity (Table 5).

\section{DISCUSSION}

We report a seroprevalence of Brucella spp. among rural people of $11.1 \%$ (with a range between provinces from $2.3 \%$ to $22.6 \%$ ) and an annual incidence of 229 per 100 000. The high incidence in the study likely reflects an increase in human brucellosis after 


\begin{tabular}{|c|c|c|c|c|c|}
\hline $\begin{array}{l}\text { Characteristic } \\
\text { Age group (years) }\end{array}$ & $\begin{array}{c}\text { Number of } \\
\text { participants }\end{array}$ & \multicolumn{2}{|c|}{$\begin{array}{c}\text { Number } \\
\text { seropositive (\%) }\end{array}$} & OR (95\% Cl) & $p$ value \\
\hline $4-9$ & 39 & 1 & (2.6) & 1.0 & - \\
\hline $10-14$ & 69 & 4 & (5.8) & $2.3(1.2-4.1)$ & 0.440 \\
\hline 15-19 & 96 & 3 & (3.1) & $1.2(0.6-2.7)$ & 0.864 \\
\hline $20-44$ & 1769 & 171 & $(9.7)$ & $3.9(1.2-7.6)$ & 0.151 \\
\hline 45 and above & 883 & 137 & $(15.5)$ & $6.6(4.5-10.2)$ & 0.046 \\
\hline \multicolumn{6}{|l|}{ Sex } \\
\hline Males & 1181 & 132 & $(11.2)$ & 1.0 & - \\
\hline Females & 1675 & 184 & $(10.9)$ & $1.0(0.9-1.2)$ & 0.968 \\
\hline \multicolumn{6}{|l|}{ Occupation } \\
\hline Herder & 2260 & 263 & $(11.6)$ & $1.3(0.9-2.5)$ & 0.087 \\
\hline Student & 142 & 4 & (3.0) & $0.9(0.3-2.5)$ & 0.345 \\
\hline Office worker & 96 & 7 & (7.3) & $0.7(0.2-1.6)$ & 0.267 \\
\hline Worker & 70 & 7 & $(10.0)$ & $0.9(0.5-2.0)$ & 0.733 \\
\hline Retired & 37 & 7 & (18.9) & $2.0(0.8-4.2)$ & 0.112 \\
\hline Veterinarian & 20 & 6 & $(30.0)$ & $3.5(1.6-7.9)$ & 0.016 \\
\hline Entrepreneur & 18 & 4 & (22.2) & $2.3(1.0-4.6)$ & 0.119 \\
\hline Unemployed & 16 & 1 & (6.3) & $0.5(0.3-1.3)$ & 0.521 \\
\hline Children under six & 13 & 1 & $(7.7)$ & $0.7(0.3-1.6)$ & 0.708 \\
\hline Other & 184 & 16 & $(8.7)$ & $0.8(0.4-1.7)$ & 0.328 \\
\hline \multicolumn{6}{|l|}{ Risk factors } \\
\hline Animal obstetric work & 778 & 93 & $(11.9)$ & $1.5(0.9-2.5)$ & 0.121 \\
\hline Contact with aborted animal fetuses and placentas & 769 & 104 & $(13.5)$ & $1.4(1.0-2.1)$ & 0.016 \\
\hline Consumption of raw milk & 295 & 32 & $(10.8)$ & $1.2(0.7-1.8)$ & 0.546 \\
\hline Consumption of raw liver & 38 & 11 & $(28.9)$ & $0.8(0.5-1.2)$ & 0.612 \\
\hline Consumption of undercooked liver & 1067 & 146 & $(13.7)$ & $1.5(0.9-4.3)$ & 0.001 \\
\hline Consumption of fresh animal blood & 143 & 12 & $(8.4)$ & $1.5(1.0-1.7)$ & 0.332 \\
\hline
\end{tabular}

the transition in Mongolia from socialism to a market economy leading to livestock privatization and collapse of the veterinary sector. ${ }^{4}$

Although several earlier studies also estimated the seroprevalences of Brucella spp. in Mongolia among high-risk people including herders, veterinarians and raw animal processing technicians, ${ }^{11-14}$ these differed from our study in time, study design and methodology and should not be compared. The result from our study was higher than the $0.1 \%$ to $10.1 \%$ reported among high-risk people in other countries, ${ }^{10,15-21}$ which is not surprising as Mongolia is ranked second in the world for brucellosis incidence. ${ }^{5}$ We also estimated a much higher incidence compared with that reported from notification data, ${ }^{22}$ despite the fact that we have taken a conservative assumption that $20 \%$ of seropositive cases are clinical cases.
According to the multivariate analysis, adults aged 45 years and above and veterinarians had a higher risk for brucellosis. This age group plays an important role in livestock herding and birthing, and veterinarians have direct contact with animals and aborted materials when doing veterinary examinations. We also found seropositives in all age groups, including in young children (four to nine years), which may indicate ongoing exposure and transmission of brucellosis in rural Mongolia. These groups should be targeted with material about protection against brucellosis infection.

This study will serve as a baseline of the seroprevalence of Brucella spp. in rural people in Mongolia before the implementation of a nationwide livestock vaccination campaign; it also will be used for ongoing brucellosis surveillance. A decrease of human incidence and repeated sero-surveillance surveys 
Table 4. Reported clinical symptoms among study participants by age group and sex, Mongolia, 2010 to 2012 $(\mathrm{N}=2856)$

\begin{tabular}{|c|c|c|c|c|c|c|c|c|c|c|}
\hline \multirow{3}{*}{ Symptoms } & \multirow{3}{*}{$\mathbf{n}$} & \multirow{3}{*}{$\begin{array}{c}0-9 \\
\%\end{array}$} & \multicolumn{4}{|c|}{ Age group } & \multicolumn{4}{|c|}{ Sex } \\
\hline & & & $10-14$ & $15-19$ & $20-44$ & $\begin{array}{l}45 \text { and } \\
\text { above }\end{array}$ & $p$ value* & Male & Female & $p$ value* \\
\hline & & & $\%$ & $\%$ & $\%$ & $\%$ & & $\%$ & $\%$ & \\
\hline Fever & 135 & 0.7 & 1.6 & 0.7 & 52.6 & 44.4 & 0.009 & 3.8 & 5.4 & 0.053 \\
\hline Headache & 1268 & 0.3 & 0.7 & 2.0 & 57.9 & 39.1 & $<0.001$ & 34.3 & 51.8 & $<0.001$ \\
\hline Joint pain & 1287 & 0.4 & 0.5 & 1.5 & 50.7 & 46.9 & $<0.001$ & 38.7 & 49.5 & $<0.001$ \\
\hline Back pain & 1351 & 0.1 & 0.4 & 1.4 & 57.6 & 40.5 & $<0.001$ & 43.6 & 49.8 & 0.001 \\
\hline Muscle pain & 590 & 0.5 & 1.0 & 1.0 & 46.4 & 51.1 & $<0.001$ & 14.9 & 24.7 & $<0.001$ \\
\hline Weakness & 964 & 0.3 & 0.3 & 0.4 & 50.7 & 48.3 & $<0.001$ & 26.9 & 38.6 & $<0.001$ \\
\hline Night sweats & 336 & 0.9 & 0.6 & 0.6 & 45.8 & 52.1 & $<0.001$ & 11.4 & 12.0 & 0.812 \\
\hline Sleeping disturbance & 530 & 0.2 & - & 0.4 & 42.3 & 57.1 & $<0.001$ & 14.5 & 21.4 & $<0.001$ \\
\hline Weight loss & 233 & 1.3 & 1.3 & 1.3 & 40.7 & 55.4 & $<0.001$ & 7.2 & 8.8 & 0.115 \\
\hline Miscarriage & 31 & - & - & - & 90.3 & 9.7 & 0.015 & - & 100.0 & $<0.001$ \\
\hline Testicular pain & 10 & - & - & - & 50.0 & 50.0 & 0.749 & 100.0 & - & $<0.001$ \\
\hline
\end{tabular}

* Either derived from the $\chi^{2}$ test or Fisher's exact test.

Table 5. Reported clinical symptoms by sero-status among study participants, Mongolia, 2010 to 2012 $(\mathrm{N}=2856)$

\begin{tabular}{|c|c|c|c|c|c|}
\hline \multicolumn{2}{|l|}{ Clinical symptoms } & \multirow{2}{*}{$\begin{array}{c}\text { Number of participants } \\
2721\end{array}$} & \multicolumn{2}{|c|}{ Number seropositive (\%) } & \multirow[t]{2}{*}{$p$ value } \\
\hline Fever & No & & 301 & $(11.1)$ & \\
\hline & Yes & 135 & 15 & (11.1) & 0.561 \\
\hline \multirow[t]{2}{*}{ Headache } & No & 1588 & 167 & $(10.5)$ & \\
\hline & Yes & 1268 & 149 & (11.8) & $<0.001$ \\
\hline \multirow[t]{2}{*}{ Joint pain } & No & 1569 & 155 & $(9.9)$ & \\
\hline & Yes & 1287 & 161 & $(12.5)$ & 0.014 \\
\hline \multirow[t]{2}{*}{ Back pain } & No & 1505 & 151 & $(10.0)$ & \\
\hline & Yes & 1351 & 165 & $(12.2)$ & 0.038 \\
\hline \multirow[t]{2}{*}{ Muscle pain } & No & 2266 & 234 & $(10.3)$ & \\
\hline & Yes & 590 & 82 & $(13.9)$ & 0.009 \\
\hline \multirow[t]{2}{*}{ Weight loss } & No & 2623 & 287 & $(10.9)$ & \\
\hline & Yes & 233 & 29 & $(12.4)$ & 0.379 \\
\hline \multirow[t]{2}{*}{ Weakness } & No & 1892 & 194 & $(10.3)$ & \\
\hline & Yes & 964 & 122 & $(12.7)$ & 0.058 \\
\hline \multirow[t]{2}{*}{ Night sweats } & No & 2520 & 266 & $(10.6)$ & \\
\hline & Yes & 336 & 50 & $(14.9)$ & 0.013 \\
\hline \multirow[t]{2}{*}{ Sleeping disturbance } & No & 2326 & 242 & $(10.4)$ & \\
\hline & Yes & 530 & 74 & $(14.0)$ & 0.010 \\
\hline \multirow[t]{2}{*}{ Miscarriage } & No & 1644 & 182 & (11.1) & \\
\hline & Yes & 31 & 2 & $(6.4)$ & 0.713 \\
\hline \multirow[t]{2}{*}{ Testicular pain } & No & 1171 & 131 & $(11.2)$ & \\
\hline & Yes & 10 & 1 & $(10.0)$ & 0.620 \\
\hline
\end{tabular}


in humans will indirectly assess the efficacy of the Funding vaccination campaign in livestock. ${ }^{23}$

There were several limitations to the study. First, association between human and livestock seropositivity was not assessed in provinces (with the exception of Zavkhan and Sukhbaatar ${ }^{7}$ ). There also may have been temporal variations in risk factors for childhood brucellosis, interpretation of reported clinical symptoms for brucellosis based on seropositivity and pathogen exposure that were not captured by the cross-sectional study design.

\section{CONCLUSION}

Our study confirms that human brucellosis seroprevalence among rural people in Mongolia is high and that the incidence is much higher than the notification data suggests. As recommended by the Food and Agriculture Organization of the United Nations, the World Organization for Animal Health and the World Health Organization, mass livestock vaccination is required in Mongolia in the mobile livestock production system.

Safety measures to avoid brucellosis include wearing protective clothes such as gloves, using metal hooks to collect aborted fetuses and placentas for burial or burning, washing hands after handling livestock and completely cooking liver from small ruminants. This information should be included in educational materials to prevent as many as possible new cases, especially at the beginning of the mass vaccination campaign while strains still circulate. We have developed written and pictorial educational materials mainly for children. The literacy rate in Mongolia is extremely high and thus printed media are appropriate. In parallel, the surveillance, treatment and diagnostic capacities for human brucellosis must be increased in provinces and districts. Education and awareness programmes should be implemented particularly before the livestock birthing season.

\section{Conflicts of interests}

None declared.
The study was carried out in Sukhbaatar and Zavkhan provinces in 2010 with funding from the Swiss Agency for Development and Cooperation in Mongolia. We thank the Mongolian Ministry of Health, the Health Promotion Foundation of Mongolia and the Research Institute of Veterinary Medicine for funding the study in 20112012. We also wish to thank the staff of these agencies for their assistance on the study.

\section{Acknowledgements}

We would like to thank the health departments of the Arkhangai, Khuvsgul, Selenge, Uvs, Umnugovi, GoviAltai, Zavkhan and Sukhbaatar provinces and districts, the physicians and the laboratory personnel for assisting with data collection.

\section{References:}

1. Corbel MJ. Brucellosis in Humans and Animals. Geneva, Food and Agriculture Organization of the United Nations, World Organization of Animal Health, World Health Organization, 2006.

2. Dean AS et al. Clinical manifestation of Human brucellosis: A systematic review and meta-analysis. PLoS Neglected Tropical Diseases, 2012, 6(12):e1929. doi:10.1371/journal. pntd.0001929 pmcid:3516581

3. Madkour MM. Madkour's brucellosis. 2nd edition. New York Springer-Verlag, 2001,1-32.

4. Roth $F$ et al. Human health benefits from livestock vaccination for brucellosis: case study. Bulletin of the World Health Organization, 2003, 81:867-876. pmid:14997239

5. Pappas $\mathrm{G}$ et al. The new global map of human brucellosis. Lancet Infectious Diseases, 2006, 6:91-99. doi:10.1016/S14733099(06)70382-6 pmid:16439329

6. Nansalmaa M et al. Result of seroprevalence study on brucellosis and other infectious diseases. Ulaanbaatar, Report of State Central Veterinary and Hygiene Laboratory, 2012, 46-57.

7. Zolzaya B et al. Representative seroprevalences of human and livestock brucellosis in two Mongolian provinces. EcoHealth, 2014, 11:356-371. doi:10.1007/s10393-0140962-7 pmid:25012215

8. Annual report of communicable diseases. Ulaanbaatar, National Center for Communicable Diseases, 2009, 17-18.

9. Díaz $\mathrm{R}$ et al. The Rose Bengal Test in human brucellosis: a neglected test for the diagnosis of a neglected disease. PLOS Neglected Tropical Diseases, 2011, 5:e950. doi:10.1371/ journal.pntd.0000950 pmid:21526218

10. Bonfoh B et al. Representative seroprevalences of brucellosis in humans and livestock in Kyrgyzstan. EcoHealth, 2012, 9:132138. doi:10.1007/s10393-011-0722-x pmid:22143553 
11. Dashdavaa J. Clinical and epidemiological situation of brucellosis in Republic of Mongolia [dissertation]. Ulaanbaatar, 1969, 55-91.

12. Baldandorj TS. Epidemiology and prevention of brucellosis in Republic of Mongolia [dissertation]. Ulaanbaatar, 1972, 50-71.

13. Gombosuren T. Epidemiological situation of brucellosis in Republic of Mongolia [dissertation]. Ulaanbaatar, 1982, 4869

14. Dagvadorj Ya et al. Human brucellosis prevalence in Mongolia. Journal of Mongolian Medicine, 2003, 1:21-22.

15. Omer MK et al. Prevalence of antibodies to Brucella spp. and risk factors related to high-risk occupational groups in Eritrea. Epidemiology and Infection, 2002, 129:85-91. doi:10.1017/ S0950268802007215 pmid:12211600

16. Cetinkaya Z et al. Seroprevalence of human brucellosis in a rural area of Western Anatolia, Turkey. Journal of Health, Population, and Nutrition, 2005, 23:137-141. pmid:16117365

17. Holt HR et al. Brucella spp. infection in large ruminants an endemic area of Egypt: cross-sectional study investigating seroprevlance, risk factors and livestock owner's knowledge. attitudes and practices (KAPs). BMC Public Health, 2011, 11:341. doi:10.1186/1471 2458-11-341 pmid:21595871
18. Rahman AK et al. Seroprevalence and risk factors for brucellosis in a high-risk group of individuals in Bangladesh. Foodborne Pathogens and Disease, 2012, 9:190-197. doi:10.1089/ fpd.2011.1029 pmid:22300225

19. Ali $S$ et al. Seroprevalence and risk factors associated with brucellosis as a professional hazard in Pakistan. Foodborne Pathogens and Disease, 2013, 10:500-505. doi:10.1089/ fpd.2012.1360 pmid:23560424

20. Dean AS et al. Epidemiology of brucellosis and $Q$ Fever in linked human and animal populations in northern Togo. PLoS ONE, 2013, 8:e71501. doi:10.1371/journal.pone.0071501 pmid:23951177

21. Ron-Román J et al. Human brucellosis in northwest Ecuador: typifying Brucella spp., seroprevalence, and associated risk factors. Vector Borne and Zoonotic Diseases, 2014, 14:124133. doi:10.1089/vbz.2012.1191 pmid:24410144

22. Ebright JR, Altantsetseg T, Oyungerel R. Emerging infectious diseases in Mongolia. Emerging Infectious Diseases, 2003, 9:1509-1515. doi:10.3201/eid0912.020520 pmid: 14720388

23. Roth $\mathrm{F}$ et al. Guidebook for the control of brucellosis in the Mongolian nomadic husbandry system. Ulaanbaatar, Health Project of Swiss Development Agency in Mongolia, 2012, 27. 